\title{
FDA warns on primate xenotransplants
}

[PARIS] The US Food and Drug Administration (FDA) has announced a de facto ban on clinical trials of xenotransplants - transplants of living cells, tissues and organs from non-human primates to humans.

"Recipients, their close contacts, and the public at large would be exposed to significant infectious disease risk," the FDA warned last week in an unusually strong statement.

The step marks formal acknowledgement by the FDA of widespread concern over the risk that animal viruses might jump to recipients and then spread to other humans, causing man-made pandemics (Nature 391, 320-325; 1998).

Phil Noguchi, director of the FDA's division of cellular and gene therapies, says that the move was prompted by a "groundswell" of public and scientific opinion over the past two years that "non-human primates are a potential hazard".

Primates seem attractive as donors, because their tissues and organs are more like those of humans than are those from more phylogenetically distant animals such as pigs, and are therefore less susceptible to rejection. But primates are widely considered unsuitable as a source of xenotransplants (Nature 392, 11-12; 1998).

One reason is that the infectious disease risk is widely considered to be unacceptably high. Ebola and Marburg monkey viruses have caused large disease outbreaks in humans, while there is compelling evidence that HIV originated from monkey retroviruses. Moreover, it would be impractical to breed the large numbers of 'clean' animals that would be needed to make any realistic impact on the organ shortage.

The new FDA "guideline to industry" (see http://www.fda.gov/cber/gdlns/xenoprim. txt) does not explicitly forbid xenotransplants from non-human primates. But in practice the guideline does amount to a ban - it warns clinical trial sponsors that there is no point applying to FDA for approval of protocols involving such xenotransplants, since they will not be able to satisfy the FDA that it is safe.

"It took a while to craft the language," says Noguchi. The FDA feels that its remit is to rule on individual submitted trial protocols, he comments. It considers that decisions concerning a formal ban or moratorium on the technology should be taken by the US Department of Health and Human Services. The department is already in the process of setting up a federal xenotransplantation advisory committee, along the lines of the National Institutes of Health's Recombinant DNA Advisory Committee.

The FDA move has been widely welcomed. "I applaud the FDA for taking a leadership role here", says Jon Allan, a virologist

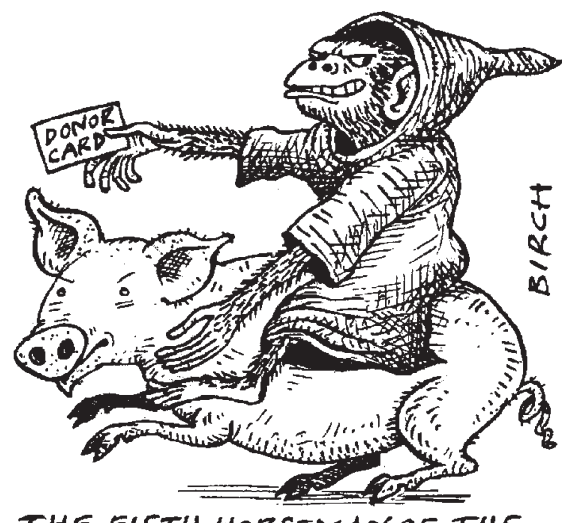

THE FIFTH HORSEMAN OF THE APOCALYPSE?

at the Southwest Foundation for Biomedical Research in San Antonio, Texas, and a member of the FDA advisory subcommittee on xenotransplantation. He says it will send a strong message internationally about the unsuitability of primates for this purpose.

But Alix Fano, of the Campaign for Responsible Transplantation, is one of several critics who say that "an out-and-out ban would have been preferable". Critics also argue that the ban sends the implicit message that species other than non-human primates — such as pigs, the current donor of choice - are therefore safe.

Fritz Bach, a xenotransplant scientist at Harvard Medical School, complains that the FDA position is confusing. "It's not unlikely that non-human primates are more dangerous in terms of disease transmission than pigs," he says. "However, we know nothing about how dangerous it would be to use pigs. Given that, how can the FDA now suggest a moratorium on non-human primate donors but maintain a policy potentially allowing pigs as donors?"

Paul Herrling, the research director of
Novartis, says that the FDA statement is "fully in line with company thinking; we think pigs are safer".

But the FDA does not necessarily support the use of pigs. "On a scientific basis, so far the dangers of non-human primates have been better demonstrated," says Noguchi. "But that does not mean that other species will or will not be a danger."

Indeed, this month Malaysia decided to slaughter 1.3 million pigs to try to contain an outbreak of Hendra virus, a disease that has jumped from pigs to humans and has already killed more than 70 people (see http://www. cdc.gov/epo/mmwr/preview/mmwrhtml/ 00056866.htm).

"In terms of virology there is evidence that the most damaging viruses can be those that cross widely disparate [species] barriers," adds Louisa Chapman, a xenotransplantation expert at the US Centers for Disease Control (CDC). "CDC is therefore very reluctant to sign on to any argument for saying primates are more dangerous than pigs."

At the same time, she believes that the tight husbandry rules envisaged in Public Health Service guidelines on xenotransplantation - which are scheduled for release this summer - would prevent such a virus from being a problem in trials in the United States.

Noguchi cautions, however, that the Hendra virus outbreak "once again reminds us that every time we use living animals' cells, tissues or organs there is a chance of something very bad happening".

Several clinical trials of pig cell transplants are under way in the United States. But the Hendra virus will cause the FDA to think carefully, says Noguchi. "If we think that xenotransplantation using pigs is not safe we will stop it," he says. "Meanwhile we want to move ahead carefully."

DeclanButler

\section{Serb scientists call for help to end bombing}

[MUNICH] Serbian scientists have called on colleagues in NATO countries to oppose the bombing campaign in Serbia and Kosovo.

The scientists have sent e-mail messages to academic research institutions around the world. They point out that many scientists resisted the Milosevic government's attack on the independence of Serbian universities last year, and helped to force his government to admit defeat in the 1996 elections won by the opposition (see Nature 394, 715; 1998). The election climbdown was achieved through "three bitter winter months of peaceful demonstrations in rain and snow".

Scientists at the Institute of Molecular Genetics and Genetic Engineering in Belgrade say the fact that NATO is bombing the cities ruled by the opposition "has led to the common feeling that NATO is against all people in Yugoslavia".

Scientists at the institute appear not to have been worn down completely by the international sanctions imposed against Serbia in 1992.

Despite the difficulties of importing chemicals, equipment and journals, and the absence of international collaboration, they have been able to keep up some research. Many have also had work published in international journals. The researchers have even managed to complete a new building, which was opened last October.

But now, they say, they travel to work in fear that they will find their laboratory destroyed by bombs, and travel home in fear of being hit themselves. Alison Abbott 